\title{
HENOCH-SCHONLEIN PURPURA - CLINICAL AND INVESTIGATIVE STUDY OF 20 PATIENTS
}

\author{
Padmasri Somala Y1, Konakanchi Venkata Chalam², P. Guruprasad ${ }^{3}$, P. Anila Sunandini ${ }^{4}$ \\ ${ }_{1}^{1}$ Senior Resident, Department of Dermatology Venereology and Leprosy, Andhra Medical College. \\ ${ }^{2}$ Assistant Professor, Department of Dermatology Venereology and Leprosy, Andhra Medical College. \\ 3 Professor, Department of Dermatology Venereology and Leprosy, Andhra Medical College. \\ 4 Professor, Department of Dermatology Venereology and Leprosy, Andhra Medical College.
}

\begin{abstract}
BACKGROUND
Henoch-Schonlein Purpura (HSP) is a systemic small vessel vasculitis with multiorgan involvement characterised by palpable purpura, arthritis, abdominal pain and renal disease. The aetiology and clinical features are varied but histopathology is characterised by leucocytoclasia with deposition of IgA immune complexes.

Aims and Objectives- The present study was done to know the spectrum of various cutaneous manifestations, systemic involvement and aetiology of Henoch-Schonlein purpura.
\end{abstract}

ABSTRACT

\section{MATERIALS AND METHODS}

The study was carried out on patients who were clinically diagnosed as Henoch-Schonlein purpura fulfilling EULAR criteria, attending the Outpatient Department of Dermatology, Venereology and Leprosy, King George Hospital, affiliated to Andhra Medical College, Visakhapatnam from January 2014 to December 2015. It is a cross-sectional type of study and a total of 20 cases were studied.

Inclusion Criteria- All patients attending to OPD, clinically diagnosed as Henoch-Schonlein purpura fulfilling EULAR criteria, irrespective of age and sex were included in study.

Exclusion Criteria- Patients with thrombocytopenic purpura, disorders of coagulation and on warfarin/heparin treatment.

\section{RESULTS}

Out of 20 patients enrolled in study, most common age group is in between 0-20 years, female preponderance, all patients presented acutely with lesions less than 6 weeks duration, $60 \%$ of patients had symptoms of burning and itching in lesions, 30\% had pain in lesions, $30 \%$ had history of low grade fever, $80 \%$ of patients had arthralgia, $65 \%$ had gastrointestinal symptoms, $30 \%$ had history of sore throat, none had history of significant drug exposure within 6 weeks of onset of lesions. Majority of patients had elevated ESR (70\%). $30 \%$ of patients had ASO titres positive, of which only $15 \%$ had throat swab positive for beta-haemolytic streptococci, ANA titres were negative in all patients, renal involvement in the form of albuminuria was seen in $30 \%$ and haematuria in $20 \%$. Out of $30 \%$ of patients with renal involvement only $5 \%$ had significant renal impairment with elevated blood urea and serum creatinine levels. Histopathology of all patients showed leucocytoclastic vasculitis with deposition of IgA.

\section{CONCLUSION}

In the present study, aetiology in most of patients is idiopathic but upper respiratory tract infection was found to be the commonest aetiology among others. So, infections like sore throat should be ruled out as prompt treatment. All presented with arthralgia but gastrointestinal tract involvement was also high with presentation as acute abdomen in one patient. Renal involvement was present in $30 \%$ but there is renal impairment in $5 \%$ of patients.

\section{KEYWORDS}

Henoch-Schonlein Purpura, Arthritis, Pain Abdomen, Renal Involvement.

HOW TO CITE THIS ARTICLE: Somala PY, Chalam KV, Guruprasad P, et al. Henoch-Schonlein purpura- Clinical and investigative study of 20 patients. J. Evolution Med. Dent. Sci. 2017;6(92):6618-6620, DOI: 10.14260/jemds/2017/1434

\section{BACKGROUND}

Henoch-Schonlein purpura (HSP) is a systemic small vessel vasculitis with multiorgan involvement characterised by palpable purpura, arthritis, abdominal pain and renal disease. The aetiology and clinical features are varied but histopathology is characterised by leucocytoclasia with deposition of IgA immune complexes. [1,2]

'Financial or Other Competing Interest': None.

Submission 10-11-2017, Peer Review 22-11-2017,

Acceptance 24-11-2017, Published 04-12-2017.

Corresponding Author:

Dr. Konakanchi Venkata Chalam,

Assistant Professor,

King George Hospital,

Visakhapatnam.

Andhra Pradesh.

E-mail:drkvchalam99@yahoo.com

DOI: $10.14260 /$ jemds $/ 2017 / 1434$

\section{MATERIALS AND METHODS}

The study was carried out on patients who were clinically diagnosed as Henoch-Schonlein purpura, attending the Outpatient Department of Dermatology, Venereology and Leprosy, King George Hospital, affiliated to Andhra Medical College, Visakhapatnam from January 2013 to December 2013. It is a cross-sectional type of study and a total of 20 cases were studied.

\section{Inclusion Criteria}

All patients attending to OPD, clinically diagnosed as HenochSchonlein purpura fulfilling EULAR criteria, [3] irrespective of age and sex were included in study. The criteria to diagnose HSP include Palpable purpura, (mandatory) $+\geq$ one of the following: 1. Diffuse abdominal pain. 2. Histopathology: typical LCV with predominant IgA deposits or proliferative glomerulonephritis with predominant IgA deposits. 3. 
Arthritis or arthralgia. 4. Renal involvement (Proteinuria and/or haematuria). All patients who are fulfilling EULAR criteria were included for clinical, aetiological and laboratory correlation.

\section{Exclusion Criteria}

Patients with thrombocytopenic purpura, disorders of coagulation and on warfarin/heparin treatment.

The study protocol included detailed history and clinical examination. The following investigations were done: complete haemogram, renal and liver function tests, urine analysis, antinuclear antibody (ANA), antineutrophilic cytoplasmic antibody (ANCA), Rheumatoid factor (RF), Creactive protein (CRP), cryoglobulins, lupus anticoagulant, HBsAg, anti-HCV antibody, antistreptolysin O (ASO) titre, throat swab for culture and sensitivity, Chest X-ray and Mantoux test. Other tests carried out depending upon the clinical indications included stool for occult blood, 24-hour urinary protein, sputum for acid-fast bacilli (AFB), HBV RNA, Anti-HBc IgM, dsDNA, anti-Ro/anti-La antibody, IgA, IgG, IgM, C3, HIV serology, X-ray of wrist and feet, arterial and venous Doppler, ultrasonography (USG) abdomen, echocardiography, renal biopsy, contrast-enhanced computed tomography of chest, digital subtraction angiography (DSA) and contrastenhanced magnetic resonance angiography. Two skin biopsies (punch biopsy, $4 \mathrm{~mm}$ ) were taken in all cases, one each for routine histopathology and direct immunofluorescence (DIF).

\section{RESULTS}

20 patients who were clinically diagnosed as HenochSchonlein purpura and histologically confirmed as leucocytoclastic vasculitis with deposition of IgA immune complexes were included in the study and all parameters were evaluated. Out of 20 patients enrolled in study, most common age group is in between $0-20$ years around $70 \%$ remaining patients belong to age group of $>40$ years [Table 1]. Out of $70 \%$ of patients who were of age group less than 20 years, majority of patients belong to age group of 11-15 years. There was female preponderance with male to female ratio of 1:1.8 [Table 2]. All patients presented acutely with lesions less than 6 weeks duration, $60 \%$ of patients had symptoms of burning and itching in lesions, 30\% had pain in lesions, 30\% had history of low grade fever, $80 \%$ of patients had arthralgia, $65 \%$ had gastrointestinal symptoms, $30 \%$ had history of sore throat, none had history of significant drug exposure within 6 weeks of onset of lesions [Table 3]. Majority of patients had elevated ESR (70\%). 30\% of patients had ASO titres positive, of which only $15 \%$ had throat swab positive for betahaemolytic streptococci, ANA titres were negative in all patients, renal involvement in the form of albuminuria was seen in $30 \%$ and haematuria in $20 \%$. Out of $30 \%$ of patients with renal involvement only $5 \%$ had significant renal impairment with elevated blood urea and serum creatinine levels [Table 4]. Histopathology of all patients showed leucocytoclastic vasculitis with deposition of IgA.

\begin{tabular}{|c|c|}
\hline Age Distribution & Number of Patients \\
\hline $0-20$ years & 14 \\
\hline & 6 \\
\hline >20 years & 6 . Age Distribution in Present Study \\
\hline \multicolumn{2}{|c|}{ Table 1. Age } \\
\hline
\end{tabular}

\begin{tabular}{|c|c|}
\hline Sex Distribution & Number of patients \\
\hline Males & 13 \\
\hline Females & 7 \\
\hline \multicolumn{2}{|c|}{ Table 2. Sex Distribution in Present Study } \\
\hline
\end{tabular}

\begin{tabular}{|c|}
\hline Systemic symptoms \\
\hline Fever \\
\hline Sore throat \\
\hline Upper respiratory infection other than sore throat \\
\hline Pain abdomen \\
\hline Arthralgia \\
\hline Haematuria \\
\hline Table 3. Systemic Symptoms
\end{tabular}

\begin{tabular}{|c|}
\hline Laboratory investigations \\
\hline Elevated total leucocyte count \\
\hline Elevated ESR \\
\hline Haematuria \\
\hline Albuminuria \\
\hline Elevated blood urea and serum creatinine \\
\hline Table 4. Investigations \\
\hline
\end{tabular}

\section{DISCUSSION}

Henoch-Schonlein purpura is a systemic self-limited small vessel vasculitis with multiorgan involvement characterised by palpable purpura, arthritis, abdominal pain and renal disease. The aetiology and clinical features are varied but histopathology is characterised by leucocytoclasia with deposition of IgA immune complexes. It is the most common childhood vasculitis, with an annual incidence of about 10 cases per 100,000.[1] HSP was announced in association with infections, medications, vaccination. The HSP children are mainly between the ages of 5 and 15 years. ${ }^{[2]}$ In the present study, most common age group presented was 0-20 years around $70 \%$ followed by $20-40$ years (30\%) which was consistent with studies done by Salusbury et al. Out of $70 \%$ of patients presented between $0-20$ years, most of the patients belong to age group of 11-15 years. In the present study, there is a female preponderance of $65 \%$ which was in consistence with studies done by Calvino et al, ${ }^{[4]}$ but contrast with studies done by Salusbury and Chen et al.[2,5]

The aetiology was idiopathic in most cases around $60 \%$ followed by infections in around $40 \%$. Out of $40 \%$ of patients, $30 \%$ had preceding sore throat having ASO titre positivity. Out of $30 \%$ of patients only $15 \%$ of patients' beta-haemolytic streptococci was isolated on culture and sensitivity and in remaining $15 \%$ Streptococcus pneumonia was isolated. Remaining $10 \%$ of patients with infectious aetiology had preceding upper respiratory tract infection as viral rhinitis. This was in consistence with the studies done by Salusbury et al.[2] Some authors had reported the trigger events including vaccinations, insect bites, and drugs have been connected with HSP[6,7]

In the present study, all patients presented with purpura. This was in consistence with the previous studies. Lesions extended above waist in $20 \%$. Out of 20 patients, two had superficial ulcers and one patient who was a female child presented with ulcerations and purpura over perineum. The most common symptoms at the site of lesion was itching and burning which was seen in $60 \%$ and $30 \%$ had pain at the site of lesion. Majority of the patients presented with arthralgia around $80 \%$, knee and ankle joints were commonly involved which was in consistence with the previous studies.[8] $30 \%$ of 
patients had haematuria and $65 \%$ of patients had abdominal pain.

In routine laboratory investigations, $40 \%$ had elevated total leucocyte count, 70\% had elevated ESR. On routine urine analysis, $20 \%$ had haematuria and 30\% had albuminuria. Out of $30 \%$ of patients with renal involvement, only $5 \%$ had significant renal impairment with elevated blood urea and serum creatinine. This is not correlating with advanced age and lesions above the waist as the study sample size was less. All the patients showed leucocytoclastic vasculitis on histopathology H\&E stain of skin biopsy specimen from the lesion. On direct immunofluorescence examination, all showed IgA deposits in the vessel walls. Out of twenty patients, four showed additional deposits of IgG and complement.

\section{CONCLUSION}

In the present study, aetiology in most of the patients is idiopathic, but upper respiratory tract infection was found to be the commonest aetiology among others. So, infections like sore throat should be ruled out for prompt treatment. Systemic manifestations like arthralgia, abdominal pain and haematuria was present in present study. But significant renal impairment was found in one patient and this was not corresponding to site of lesion and advanced age as the study sample was less.

\section{REFERENCES}

[1] Saulsbury FT. Clinical update: Henoch-Schonlein purpura. Lancet 2007;369(9566):976-8.
[2] Saulsbury FT. Henoch Schonlein purpura in children. Report of 100 patients and review of the literature. Medicine 1999;78(6):395-409.

[3] Ozen S, Ruperto N, Dillon MJ, et al. EULAR/PReS endorsed consensus criteria for the classification of childhood vasculitides. Ann Rheum Dis 2006;65(7):936-41.

[4] Calvino MC, Llorca J, Garcia-Porrua C, et al. Henoch Schonlein purpura in children from northwestern Spain: a 20-year epidemiologic and clinical study. Medicine (Baltimore) 2001;80(5):279-90.

[5] Chen O, Zhu XB, Ren P, et al. Henoch Schonlein purpura in children: clinical analysis of 120 cases. African Health Sciences 2013;13(1):94-9.

[6] Patel U, Bradley JR, Hamilton DV. Drug points: HenochSchonlein purpura after influenza vaccination. Br Med J (Clin Res Ed) 1988;296(6639):1800.

[7] Courtney PA, Patterson RN, Lee RJ. Henoch Schonlein purpura following meningitis $\mathrm{C}$ vaccination. Rheumatology (Oxford) 2001;40(3):345-6.

[8] Trapani S, Micheli A, Grisolia F, et al. Henoch Schonlein Purpura in childhood: epidemiological and clinical analysis of 150 cases over a 5-year period and review of literature. Semin Arthritis Rheum 2005;35(3):14353. 